\title{
Win-win Strategy for China's Environmental Regulation and Economic Development
}

\author{
Xiaojing CHAO * and Yuanmei LIAN \\ Northwest University, Xi'an, Shaanxi, China; chaoxiaojing1234@163.com \\ * Correspondence: chaoxiaojing1234@163.com
}

\begin{abstract}
During the period of structural adjustment of China's economic development, solving the problem of environmental pollution has become an urgent need to realize the coordinated progress of economic development and ecological environment. However, whether the process of implementing environmental regulation to govern the ecological environment will have an inhibitory effect on China's economic development has become a key issue that needs to be answered urgently. Based on the panel data of China's prefecture-level cities and listed companies from 2007 to 2017, this paper makes an empirical study on the relationship between the environmental regulation of prefecture-level cities and the development of China's listed companies. The results of mean regression and quantile regression show that the strengthening of environmental regulation has a significant positive impact on the total factor productivity of enterprises, and this promotion effect will gradually improve with the improvement of enterprise production efficiency. Therefore, there is no contradiction between strengthening the management and protection of the ecological environment and achieving the phased goal of China's high-quality economic development.
\end{abstract}

Keywords: environmental regulation; economic development; total factor productivity; listed companies

\section{JEL Classification: O1; Q5}

\section{Introduction}

Since the reform and opening up in 1978, China's economy has experienced rapid growth for more than 40 years, but this extensive growth is mainly achieved by sacrificing environmental resources. Therefore, while achieving economic prosperity, it has also brought about serious environmental problem. The report of the Nineteenth Chinese People's Congress pointed out: "China's economy has shifted from a high-speed growth stage to a high-quality development stage." Highquality development is an upgraded version of our country after more than 40 years of high-speed growth, which requires that the economic quality increase while the number of economies increases. This is an inevitable requirement for advancing the five new development concepts, breaking the current stage of economic growth, and realizing the sustainable development of China's economy on the premise that major social contradictions have changed. From an economic and environmental perspective, high-quality development is a state where economic development is in harmony with resources and the environment. Therefore, solving environmental pollution issues has become an urgent need for China's economic development and ecological environment to advance together. In March 2019, the second meeting of the Thirteenth National People's Congress of the People's Republic of China emphasized "all-round strengthening of ecological environmental protection and promoting the fight against pollution in accordance with law." Therefore, in the period of structural adjustment of economic development, whether environmental regulations can promote economic development is a key issue that needs to be solved urgently.

A few scholars have found that environmental regulation will inhibit the improvement of the quality of economic development and believe that there is an opposite trend between the two indicators (Greenstone 2014; Lei and Yu 2013; Xu and Qi 2017; Elrod 2017). At the same time, some scholars have concluded that there is a "inverted $\mathrm{N}$ " or " $\mathrm{U}$ " nonlinear relationship between environmental regulation and economic development ( $\mathrm{Li}$ and Cao 2017; Wang and Feng 2018). 
However, most scholars believe that environmental regulation can have a positive incentive effect on the improvement of the quality of economic development and further achieve a win-win situation of environmental protection and economic development (Yuan and Xie 2016; He 2018; Hering 2014; Tong 2019; Wang et al. 2016).

Xie et al. (2012) on the basis of distinguishing China's economically developed areas from the less developed areas, study shows that in China's economically developed areas, environmental regulation has a significant positive effect on economic growth, while in the less developed areas this promoting effect is not significant. Feng (2014) research believes that environmental regulation can promote China's economic growth, and under different environmental regulation intensity, the degree of impact of environmental regulation on economic growth is also different. Wu et al. (2016) took 280 key cities from 1992 to 2009 as the research objects, and took the environmental regulation policy of "two control areas" implemented in 1998 as a natural experiment. The results show that after the implementation of this environmental regulation, the per capita GDP and per capita industrial GDP of the "two control areas" cities have been improved to a certain extent, that is, environmental regulation has not restricted economic growth, but has achieved a win-win result of environmental protection and economic growth. Yuan and Xie (2016) based on the empirical research results of China's provincial panel data from 1999 to 2012 believe that technological progress is the main source of promoting industrial green total factor productivity growth. Kong Haitao, Yu Qingrui and Zhang fawn (2019) take 283 prefecture-level cities in China as samples, and the research finds that the improvement of environmental regulation level is conducive to the promotion of urban productivity, and this effect shows obvious heterogeneity among cities of different sizes and different innovation capabilities.

Based on the above analysis, the primary question to be answered in this article is whether the impact of environmental regulation on the economic development of listed companies in China is a stimulant or a suppressant. Secondly, will the extent of this impact be limited by the initial enterprise efficiency?

\section{Methodology}

The sample interval of this article is from 2007 to 2017, the data used are the operating data of Chinese listed companies and the environmental regulation data of 283 prefecture-level cities in China. Among them, the relevant data of listed companies comes from CSMAR Service Center, the prefecturelevel city environmental regulation data comes from the China City Statistical Yearbook (2007-2019). Due to the lack of data in Tibet, Hong Kong, Macau, and Taiwan provinces, we have deleted the data of listed companies registered in these provinces. While linear interpolation was used to supplement a small number of missing values, in order to avoid the influence of outliers on the regression results, a $1 \%$ bilateral tailing process was performed on all continuous variables.

Among them, this article chooses to take total factor productivity(acftfp) as the measure of the quality of China's economic development (Jin and Shen 2018). Micro-level total factor productivity is measured mainly by the Olley-Pakes method (OP), Levinsohn-Petrin method (LP), and the ACF method proposed by Ackerberg et al. (ACF). Among them, the OP method solves part of the problem of sample selection bias by using corporate investment as a proxy for productivity, and the LP method uses intermediate inputs to overcome the endogenous problem in the process of estimating Solow residual value, but because in these two methods labor input is a deterministic function of other variables, on the one hand, it is impossible to estimate the labor input coefficient, and on the other hand, there may be multicollinearity problems. With this in mind, using the ACF method to calculate total factor productivity is a more effective estimate of China's high-quality development. In specific calculations, this paper draws on the routine practices of Lu and Lian (2012), and uses the operating income, number of employees, and net fixed assets as the measurement of enterprise output, labor input, and capital investment. Cash paid for other long-term assets is used as an intermediate input indicator for the ACF method. Among them, operating income and net fixed assets were deflated using the ex-factory price index and fixed asset investment price index of the province, city, and autonomous 
region where the registration was located, and the intermediate input index was converted into the 2007 constant price using the consumer price index.

When measuring environmental regulations (enre), taking into account the availability of data from 283 prefecture-level cities in China, and the one-sidedness of using the single index method and the evaluation \& scoring method, this paper draws on Li and Zou Qing (2018), Dong and Wang (2019) thesis, using the comprehensive index method to measure the level of environmental regulations in prefecture-level cities. The specific operations of the comprehensive index method are: first, standardize the relevant basic indicators of environmental regulation; second, determine the weight of the basic indicators according to the entropy method, and further calculate the comprehensive index of environmental regulations based on the weights and standardized values. Based on the existing literature, this paper selects five basic indexes: industrial sulfur dioxide removal rate, industrial soot removal rate, comprehensive utilization rate of industrial solid waste, urban domestic sewage treatment rate, and harmless treatment rate of domestic waste.

In addition, the following control variables are selected in this article: (1) The size of the enterprise (scale) is expressed as the total assets of the company after taking the natural logarithm; (2) The purchasing power of the enterprise (purch) is measured by the year-end monetary funds after taking the natural logarithm; (3)The market value of the enterprise (value) is taken by the market value of the natural logarithm of the company; (4) The company's operating capacity (profit) is characterized by the company's return on assets; (5)The employee's salary ratio (hire) is calculated by the ratio of the listed company's payable employee's salary to the operating cost; (6) The concentration of corporate equity (share) is measured by the sum of the equity ratios of the top three shareholders of listed companies; (7) The age of the company (age) is calculated by subtracting 1 from the current year and the year of registration of the company. Among them, the scale of the enterprise, the purchasing power of the enterprise, and the proportion of employees' salaries are all converted into constant prices in 2007.

Table 1. Selection of control variables.

\begin{tabular}{|c|c|c|}
\hline Variable & Index & Measure and calculate \\
\hline scale & enterprise size & $\begin{array}{l}\text { the total assets of the company after } \\
\text { taking the natural logarithm }\end{array}$ \\
\hline purch & purchasing power & $\begin{array}{l}\text { the year-end monetary funds after taking } \\
\text { the natural logarithm }\end{array}$ \\
\hline value & market value & $\begin{array}{l}\text { the market value after taking the natural } \\
\qquad \text { logarithm }\end{array}$ \\
\hline profit & operating capacity & the company's return on assets \\
\hline hire & $\begin{array}{l}\text { percentage of employee's } \\
\text { salary }\end{array}$ & employee's salary/ operating cost ${ }^{*} 100$ \\
\hline share & $\begin{array}{c}\text { concentration of corporate } \\
\text { equity }\end{array}$ & $\begin{array}{c}\text { the sum of the equity ratios of the top } \\
\text { three shareholders }\end{array}$ \\
\hline age & enterprise age & current year-year of registration+1 \\
\hline
\end{tabular}

Table 2. Descriptive statistics of variables.

\begin{tabular}{cccccc}
\hline Variable & $\mathbf{N}$ & Mean & St. dev & Min & Max \\
\hline acftfp & 24418 & 14.1710 & 0.9486 & 11.9488 & 16.8205 \\
enre & 24418 & 1.1534 & 0.1258 & 0.4600 & 1.3500 \\
scale & 24418 & 21.7606 & 1.2785 & 19.1928 & 25.6848 \\
purch & 24418 & 19.8309 & 1.3838 & 15.8700 & 23.6768 \\
value & 24418 & 22.4023 & 1.1401 & 19.2275 & 28.5332 \\
profit & 24418 & 0.0391 & 0.0564 & -0.2072 & 0.1967 \\
hire & 24418 & 0.0338 & 0.0535 & 0.0001 & 0.3666
\end{tabular}




\begin{tabular}{cccccc} 
share & 24418 & 49.0248 & 15.6865 & 15.8600 & 85.6400 \\
age & 24418 & 16.4051 & 6.9806 & 3 & 30 \\
\hline
\end{tabular}

\section{Results}

\subsection{Construction of the economic model}

Based on the above theoretical analysis ideas, in order to capture the actual impact of environmental regulations on the quality of economic development, this article builds the following basic measurement models:

$$
\text { dequalityiwit }=\alpha_{0}+\alpha_{1} \text { enre } e_{j}+\beta X_{i w j t}+v_{w}+v_{j}+v_{t}+\varepsilon i w j t
$$

The set of control variables is:

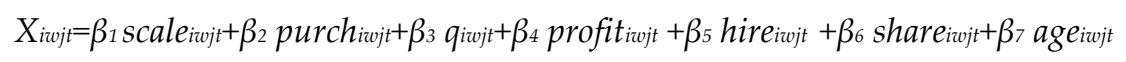

Among them, the explained variable dequalityiwjt represents the economic quality development of listed company $i$ in industry $w$ of region $j$ during the $t$ period, which is measured by the total factor productivity (acftfp) measured by ACF method. enrejt is the core explanatory variable, indicating the level of environmental regulation in area $j$ at time $t$. $X_{\text {iwjt }}$ is a set of other control variables that affect the economic development of an enterprise, including: enterprise scale (scale), enterprise purchasing power (purch), enterprise market value (q), enterprise operating capability (profit), and employee compensation (hire), Corporate equity concentration (share) and corporate age (age). $\mathrm{V}_{\mathrm{w}}, \mathrm{v}_{\mathrm{j}}, \mathrm{V}_{\mathrm{t}}$ are industry, regional and time dummy variables, respectively, reflecting industry fixed effects, regional fixed effects and time fixed effects. $\varepsilon_{i w j t}$ is a random perturbation term. The core coefficient concerned in this article is $\alpha_{1}$, and its direction and size reflect the direction and extent of the impact of regional environmental regulation on the quality of economic development.

The above basic econometric model focuses on examining the impact of environmental regulations on the quality conditions of economic development, which is essentially a mean regression and is susceptible to extreme values. In order to accurately characterize the complete statistical characteristics of the condition distribution and effectively capture the effect of environmental regulation on the quality of economic development in extreme regions, this paper further constructs the following quantile regression model:

$$
\text { dequalityiwjt }(\tau)=\beta 0(\tau)+\beta 1(\tau) \text { enrejt }+\beta(\tau) \text { Xiwjt }+v t+\varepsilon i w j t
$$

Among them, $\tau(0<\tau<1)$ represents the different quantiles of the conditional distribution, which are $0.1,0.25,0.5,0.75$, and 0.9 respectively; the core coefficient $\beta_{1}(\tau)$ reveals that the level of environmental regulation affects economic development at different quantiles. Marginal impact of quality.

\subsection{Results of the benchmark model}

In the benchmark regression section, the mixed OLS, fixed effect model, and random effect model are used to estimate the role and size of the environmental regulation level of Chinese prefecture-level cities in 2007-2017 on the development of local listed companies. Table 3 is the corresponding benchmark regression results. Model 1 reports the estimated results of controlling only time effects, regional effects, and industry effects. Every 1 unit increase in environmental regulation can increase the listed company's TFP by 0.248 , and pass the statistical significance test of $5 \%$. After controlling other enterprise characteristic variables, each unit of environmental regulation in the prefecture-level city in Model 2 can significantly change the TFP of listed companies in the region by 0.124 . This shows that after excluding other factors that affect the efficiency of listed companies, the environment the positive effect of regulation on the high-quality development of enterprises is still significant. Further, 
Model 3 and Model 4 are the estimation results using the individual time double fixed effect model, in which the estimated coefficients of environmental regulation (enre) are significantly positive at a confidence level of 1\%; Models 5 and 6 report the fitting of random effects after control of time, region, and industry. The estimated coefficients of environmental regulation (enre) are all positive, but the coefficients fail to pass the $10 \%$ significance when the other factors are not controlled test. Therefore, this paper concludes that the strengthening of environmental regulations can significantly promote the development quality of listed companies in China.

Among the control variables, the regression coefficients of enterprise scale (scale), enterprise purchasing ability (purch), enterprise value (value), enterprise operating ability (profit), equity concentration (share) and enterprise age (age) are all significantly positive. That is to say, the expansion of corporate asset scale and monetary capital scale, the increase of corporate market value and return on assets, and the growth of equity intensiveness and operating life will cause the same factor changes in the total factor productivity of listed companies. The regression coefficient of the employee's salary ratio (hire) is significantly negative, indicating that an increase in the ratio of payable employees' salary to operating costs will inhibit the improvement of corporate efficiency. This may be because an increase in the proportion of employee compensation means an increase in the labor cost of the enterprise. While increasing the cost burden of the enterprise, this change will also have a crowding out effect on the labor demand of the enterprise, which will adversely affect the productivity of listed companies (Cong and He 2018).

Table 3. Results of the Benchmark Model: Impact of Environmental Regulations on the Development of Chinese Listed Companies.

\begin{tabular}{|c|c|c|c|c|c|c|}
\hline \multirow{3}{*}{$\begin{array}{c}\text { Variable } \\
\text { Estimation }\end{array}$} & \multicolumn{6}{|c|}{ Explained variable: total factor productivity of the ACF method } \\
\hline & \multicolumn{2}{|c|}{ OLS } & \multicolumn{2}{|c|}{ Fixed effects } & \multicolumn{2}{|c|}{ Random effects } \\
\hline & (1) & $(2)$ & (3) & (4) & (5) & (6) \\
\hline \multirow[t]{2}{*}{ enre } & $0.248^{* *}$ & $0.124^{*}$ & $0.728^{* * *}$ & $0.544^{* * *}$ & 0.0377 & $0.0927^{* *}$ \\
\hline & $(0.116)$ & $(0.0664)$ & $(0.154)$ & $(0.0784)$ & $(0.0679)$ & $(0.0429)$ \\
\hline \multirow[t]{2}{*}{ scale } & & $0.340^{* * *}$ & & $0.278^{* * *}$ & & $0.308^{* * *}$ \\
\hline & & $(0.0219)$ & & $(0.0292)$ & & $(0.0170)$ \\
\hline \multirow[t]{2}{*}{ purch } & & $0.0664^{* * *}$ & & $0.127^{* * *}$ & & $0.0292^{* * *}$ \\
\hline & & $(0.0100)$ & & $(0.0130)$ & & $(0.0060)$ \\
\hline \multirow[t]{2}{*}{ value } & & $0.0883^{* * *}$ & & $0.0944^{* * *}$ & & $0.116^{* * *}$ \\
\hline & & $(0.0165)$ & & $(0.0225)$ & & $(0.0137)$ \\
\hline \multirow[t]{2}{*}{ profit } & & $1.747^{* * *}$ & & $1.725^{* * *}$ & & $1.850^{* * *}$ \\
\hline & & $(0.105)$ & & $(0.123)$ & & $(0.0822)$ \\
\hline \multirow[t]{2}{*}{ hire } & & $-4.039^{* * *}$ & & $-4.551^{* * *}$ & & $-3.815^{* * *}$ \\
\hline & & $(0.175)$ & & $(0.236)$ & & (0.193) \\
\hline \multirow[t]{2}{*}{ share } & & $0.0023^{* * *}$ & & $0.0016^{*}$ & & 0.0011 \\
\hline & & $(0.0008)$ & & $(0.0008)$ & & $(0.0007)$ \\
\hline \multirow[t]{2}{*}{ age } & & $0.0113^{* * *}$ & & $0.0138^{* * *}$ & & $0.0098^{* * *}$ \\
\hline & & $(0.0015)$ & & $(0.0027)$ & & (0.0019) \\
\hline \multirow[t]{2}{*}{ _cons } & $13.72^{* * *}$ & $2.988^{* * *}$ & $13.33^{* * *}$ & $2.658^{* * *}$ & $13.91^{* * *}$ & $3.929 * * *$ \\
\hline & $(0.159)$ & $(0.155)$ & $(0.175)$ & $(0.185)$ & $(0.126)$ & $(0.233)$ \\
\hline$v_{i}$ & NO & NO & YES & YES & NO & NO \\
\hline$v_{t}$ & YES & YES & YES & YES & YES & YES \\
\hline$v_{j}$ & YES & YES & NO & NO & YES & YES \\
\hline$v_{w}$ & YES & YES & NO & NO & YES & YES \\
\hline$N$ & 24418 & 24418 & 24418 & 24418 & 24418 & 24418 \\
\hline$R 2$ & 0.200 & 0.668 & 0.025 & 0.595 & 0.1462 & 0.6544 \\
\hline
\end{tabular}




\subsection{Results of the quantile regression}

The above basic econometric model mainly describes the positive promotion effect of environmental regulations on the quality of Chinese listed companies' economic development in the mean range, ignoring their tail status characteristics in extreme regions. Through statistical analysis, this paper finds that the skewness of total factor productivity of listed companies is 0.40 and the kurtosis is 3.09, showing a right-side thick tail distribution; while the skewness value of environmental regulations is -1.29 , and the kurtosis value is 5.11 , showing a typical Left-left thick-tailed distribution. In order to characterize the asymmetrical impact of prefecture-level environmental regulation on the quality of China's listed companies' economic development and effectively capture the tail characteristics of the TFP distribution of listed companies, this paper next uses quantile regression to control the time effect and estimates At the $0.1,0.25,0.5,0.75$, and 0.9 quantiles, listed companies' highquality development of quantile equations affected by environmental regulations. The specific regression results are shown in Table 4 . The fitting coefficients of environmental regulations (enre) are all significantly positive at a confidence level of $1 \%$, which indicates that the environmental regulations of prefecture-level cities have a significant positive promotion effect on all quantiles of the quality of China's economic development. Furthermore, the coefficient estimation of environmental regulation (enre) at different quantiles is between 0.435 and 0.664, and its magnitude shows an upward trend with the increase of quantiles, which indicates that increasing environmental regulation in prefecturelevel cities may more strongly promote efficient listed companies to improve development quality. At the same time, the regression results of most other control variables are consistent with the benchmark regression results. In a word, environmental regulation has a significant positive impact on China's economic development at different sub-sites, and its positive promotion effect on highly efficient listed companies is even stronger.

Table 4. Results of the Quantile regression: Impact of Environmental Regulations on the Development of Chinese Listed Companies.

\begin{tabular}{cccccc}
\hline Variable & \multicolumn{4}{c}{ Explained variable: total factor productivity of the ACF method } \\
\hline \multirow{2}{*}{ Estimation } & QR-10 & QR-25 & QR-50 & QR-75 & QR-90 \\
\cline { 2 - 6 } enre & $\mathbf{( 1 )}$ & $\mathbf{( 2 )}$ & $\mathbf{( 3 )}$ & $\mathbf{( 4 )}$ & $\mathbf{( 5 )}$ \\
\hline \multirow{2}{*}{ scale } & $0.435^{* * *}$ & $0.482^{* * *}$ & $0.536^{* * *}$ & $0.596^{* * *}$ & $0.664^{* * *}$ \\
& $(0.0610)$ & $(0.0436)$ & $(0.0367)$ & $(0.0515)$ & $(0.0808)$ \\
purch & $0.261^{* * *}$ & $0.268^{* * *}$ & $0.276^{* * *}$ & $0.286^{* * *}$ & $0.296^{* * *}$ \\
& $(0.0172)$ & $(0.0123)$ & $(0.0104)$ & $(0.0146)$ & $(0.0228)$ \\
\multirow{2}{*}{$q$} & $0.118^{* * *}$ & $0.122^{* * *}$ & $0.126^{* * *}$ & $0.131^{* * *}$ & $0.136^{* * *}$ \\
& $(0.0087)$ & $(0.0062)$ & $(0.0053)$ & $(0.0074)$ & $(0.0115)$ \\
profit & $0.105^{* * *}$ & $0.101^{* * *}$ & $0.0952^{* * *}$ & $0.0892^{* * *}$ & $0.0825^{* * *}$ \\
& $(0.0172)$ & $(0.0123)$ & $(0.0104)$ & $(0.0146)$ & $(0.0228)$ \\
hire & $2.294^{* * *}$ & $2.048^{* * *}$ & $1.767^{* * *}$ & $1.453^{* * *}$ & $1.101^{* * *}$ \\
& $(0.132)$ & $(0.0945)$ & $(0.0797)$ & $(0.112)$ & $(0.175)$ \\
share & $-5.072^{* * *}$ & $-4.846^{* * *}$ & $-4.589^{* * *}$ & $-4.302^{* * *}$ & $-3.981^{* * *}$ \\
& $(0.141)$ & $(0.101)$ & $(0.0848)$ & $(0.119)$ & $(0.186)$ \\
age & $0.0014^{* * *}$ & $0.0015^{* * *}$ & $0.0016^{* * *}$ & $0.0017^{* * *}$ & $0.0018^{* * *}$ \\
& $(0.0005)$ & $(0.0003)$ & $(0.0003)$ & $(0.0004)$ & $(0.0006)$ \\
vt & $0.0027^{* *}$ & $0.0075^{* * *}$ & $0.0130^{* * *}$ & $0.0191^{* * *}$ & $0.0259^{* * *}$ \\
N & $(0.0012)$ & $(0.0008)$ & $(0.0007)$ & $(0.0010)$ & $(0.0016)$ \\
\hline \multirow{2}{*}{ fi* } & $Y E S$ & $Y E S$ & $Y E S$ & $Y E S$ & $Y E S$ \\
& 24418 & 24418 & 24418 & 24418 & 24418 \\
\hline
\end{tabular}

\section{Discussion}

In order to answer the key question whether environmental regulation can promote economic development during the structural adjustment period of China's economic development, this paper 
uses mean regression and quantile regression as experiments to test whether environmental regulation can promote the development of Chinese listed companies. Compared with the existing research literature, this article mainly expands the existing research from the following two aspects: First, the existing literature tends to focus on the impact of environmental regulation on the macro level of China's economic growth. However, environmental regulation is a policy tool that works by directly acting on the micro-enterprise of an enterprise. Therefore, to clarify the impact of environmental regulation on macroeconomic development, we must answer the question whether it can promote the improvement of corporate productivity. Second, most of the existing literature is based on traditional mean methods to study the impact of environmental regulation on economic growth. This paper uses the panel quantile regression method to describe the relationship between environmental regulation and corporate productivity in different quantiles. The results show that environmental regulation has a stronger positive promotion effect on high-efficiency listed companies.

Although this article verifies the positive impact of environmental regulations on the economic development of Chinese listed companies, there are still some key questions that have not been answered, such as: What are the specific ways in which environmental regulations affect economic development? Does the role of environmental regulation in promoting economic development differ in different regions and industries? Therefore, this issue can be further studied in the future.

\section{Conclusions}

Based on the panel data of China's prefecture-level cities and listed companies from 2007 to 2017, an empirical study was conducted on the relationship between prefecture-level city environmental regulation efforts and the development of Chinese listed companies. The empirical results show that the strengthening of environmental regulations has a significant positive impact on the total factor productivity of enterprises, and this enhancement will gradually increase with the improvement of enterprise production efficiency. For this reason, this article puts forward the following suggestions: Strengthening the governance and protection of the ecological environment is not contradictory to the phased goal of achieving high-quality development of the Chinese economy. China is currently in a critical period of transition from the quantity era to the quality era. In the subsequent development process, it is unwavering to strengthen its determination to protect the environment, further strengthen environmental governance, put an end to the persistence of the undesirable growth form of "environment for growth" nationwide, and contribute China's strength to the world environmental governance.

Acknowledgments: This work was supported by Shaanxi Social Science Fund (Grant No 2019D018), Research on High Quality Development Strategy of Yellow River Basin, Special Support Plan for High-level Talents in Shaanxi Province and Support for Outstanding Young Talents in Shaanxi Province.

\section{References}

Dong Z., and Wang H. 2019. The "Local-Neighboring" Green Technological Progress Effect of Environmental Regulation. China's Industrial Economy: 1, 100-118.

Elrod A. Aaron, and Malik S. Arun. 2017. The Effect of Environmental Regulation on Plant-level Product Mix: A Study of EPA's Cluster Rule. Journal of Environmental Economics and Management: 83, 164-184. https://doi.org/10.1016/j.jeem.2017.03.002.

Feng F. 2014. Multiple Equilibrium of Environmental Regulation and Economic Growth: Theory and China's Experience. Contemporary Finance and Economics: 11, 14-24.

Greenstone Michael, Hanna Rema. 2014. Environmental Regulations, Air and Water Pollution and Infant Mortality in India. American Economic Review: 104, 3038-3072. https://doi.org/10.1257/aer.104.10.3038.

He Xiuhong. 2018. Environmental regulation and the quality of China's economic growth-an empirical analysis based on provincial panel data. Contemporary economic science: 1-10, 40, 124.

Hering Laura, and Poncet Sandra. 2014. Environmental Policy and Exports: Evidence from Chinese Cities. Journal of Environmental Economics \& Management: 68, 296-318. https://doi.org/10.1016/j.jeem.2014.06.005.

King K., and Shen K. 2018. Beggar your neighbor or partner with your neighbor? - Environmental Regulation Enforcement Interaction and Urban Productivity Growth. Managing the World: 34, 43-55. 
Kong H., Yu Q., and Zhang F. 2019. Environmental Regulation, Economic Agglomeration and Urban Productivity. Economic Issues Exploration: 1, 75-87.

Lee H., and Zou Q. 2018. Research on Environmental Regulation, Resource Endowment and Urban Industrial Transformation-Based on Comparative Analysis of Resource-based Cities and Non-resource-based Cities. Economic Research: 53, 182-198.

Lei M., and Yu X. 2013. Local Fiscal Expenditure, Environmental Regulation and China's Low Carbon Economic Transformation. Economic Science: 5, 47-61.

Li B., and Cao W. 2017. Research on the Impact of Environmental Regulation on the Performance of China's Circular Economy-Based on the Perspective of Ecological Innovation. China Soft Science: 6, 140-154.

Lu X., and Lian Y. 2012. Total Factor Productivity Estimation of Chinese Industrial Enterprises: 1999-2007. Economics (Quarterly): 11, 541-558.

Tong Fu, Chao Cai, and Ze Jian. 2019. The Illusion of "win-win" solution: Why Environmental Regulation in China Promotes Firm Performance? Structural Change and Economic Dynamics: 52, 366-373. https://doi.org/10.1016/j.strueco.2019.12.007.

Wang X., and Feng Y. 2018. The Impact of Environmental Regulation on the Performance of China's Circular Economy. China population resources and environment: 28, 136-147.

Wang Lining, Patel L. Pralit, Yu Sha et al. 2016. Win-Win Strategies to Promote Air Pollutant Control Policies and Non-fossil Energy Target Regulation in China. Applied Energy: 163, $244-253$. https://doi.org/10.1016/j.apenergy.2015.10.189.

Wu M., Zhou S., and Chen J. 2016. Can Environmental Regulation and Economic Growth Win-Win-An Empirical Study Based on China's "Two Controlled Zones". Contemporary Economic Science: 38, 44-54, 124.

Xie J., Li Y., and Han F. 2012. Environmental Regulation and Economic Growth: An Analysis Based on China's Provincial Panel Simultaneous Equations. Economic Journal: 1-5.

Xu Y., and Qi Y. 2017. Re-evaluation of the Impact of Environmental Regulation on Enterprise Productivity and Mechanism Test. Finance and Trade Economics: 38, 147-161.

Yi C., and He S. 2018. Characteristics and Effects of "Five Risks and One Pension" in China's Manufacturing Industry: Evidence from Listed Companies from 2013 to 2016. Reform: 3, 111-123.

Yuan Y., Xie R. 2016. Environmental Regulation and Industrial Green Productivity Growth-Re-examination of "Strong Porter Hypothesis". China Soft Science: 7, 144-154. 